\title{
Optimization of Ultrasonic Extraction of Total Flavonoids from Cinnamonum zeylaniccum
}

\author{
Seyma BALCI ${ }^{1}$, Sibel YIGITARSLAN *1 \\ ${ }^{1}$ Department of Chemical Engineering, Suleyman Demirel University, Isparta, Turkey
}

Received: 04 May 2017 - Revised: 28 June 2017 - Accepted: 16 July 2017

\begin{abstract}
Cancer is the most widespread disease in the world currently. The availability of using controlled-drugreleasing capsules for those cancer diseases had become more and more important. The initial operation of the production process of the capsules requires the extraction of the active ingredients from the plant. Phytochemicals exert positive effects on human health and thus they are important compounds found in medicinal plants like Cinnamonum zeylaniccum. Flavonoids are the most effective phytochemicals having more than four thousand different types and they are well known antioxidants especially used in treatments of cancer diseases. In the light of these information, the aim of this study was to optimize the ultrasonic extraction of flavonoids (as a raw-material fort he capsules) from Cinnamonum zeylaniccum with methanol by using Response Surface Methodology. Batch extraction experiments had been carried out with the parameters of solid-to-liquid ratio, extraction temperature and time, by applying ultrasounds on sweep mode. Multi-parameter optimization was carried out with threeparameter, three-level, three-centered Box-Behnken design considering the optimum values obtained in singleparameter optimization. Design-Expert software was used to obtain the function representing the extraction yield surface depending on the selected parameters. As a result of the statistical analysis, the function expressing the effect of the parameters on the resulting amount of quercetin production in industry had been derived as reduced cubic model. Solid-to-liquid ratio was found as the most effective parameter on the extraction yield. At the optimum conditions $\left(30^{\circ} \mathrm{C}, 1 / 10 \mathrm{~g} / \mathrm{ml}\right.$, and 15 minutes $), 12.34 \mathrm{mg}$ quercetin equivalent total flavonoids were extracted.
\end{abstract}

Keywords: Cinnamonum zeylaniccum, Extraction, Flavonoid, Response surface methodology

\section{INTRODUCTION}

Currently cancer is the second leading cause of the death globally. Analysis showed that about a third of the most common cancer types can be prevented through diet, weight and physical activity. Herbal plants containing phytochemicals are gaining more and more consideration especially for cancer treatments. Phytochemicals exert positive effects on human health and thus they are important compounds found in medicinal plants. In order to take acceptable amount of those phytochemicals, they should be taken as capsules. As a result, several studies focusing on producion of cancer-focusing drug delivery systems by loading phytochemicals of medicinal plants are an important subject for this area.

\footnotetext{
*Corresponding Author E-mail: yildizsibel@sdu.edu.tr
} 
Several plants have been present in different families. Cinnamon, a member of the Laurel family, native to the South and Southeast Asia, is a genus of evergreen aromatic fragrant tree. Substantially dried bark of the cinnamon tree is used in general consumption and as a spice in daily life. There are about 100 kinds of cinnamons present. Countries performing the most of cinnamon production in the World are China, Indonesia and Sri Lanka. This plant was known with its special property of releasing the ureteral and kidney stones [1].

One of the phytochemicals, flavonoids are the most effective antioxidants having more than 4000 different types $[2,3]$. They are capable of binding free radicals and they show high specificity on interacting with the cancer cells without damaging the normal ones. Those properties make them attractive for curing cancer diseases [4]. Catechin and catechin derivatives, gallic acid, and quercetin are the most common polyphenols in plants. They are found in fruits, vegetables, and also in spices $[5,6]$. One of the most important properties of the quercetin is formation of the chelates with heavy metals [3, 7-10]. It reacts with titanium-based anions in 1:2 ratios [7]. This chelate formation characteristic is especially preferred in curing of food poisoning and an adsorption of radiation [7, 9]. In some of the researches, quercetin was found to be effective on cancer treatments and curing.

The type and the amount of the flavonoids of a specific plant are strongly affected not only from the harvest date and growing conditions but also by the process conditions, especially the extraction conditions. From its first usage in nineteenth century to today, several different types of extraction techniques have been developed, namely ultrasonic, microwave, and supercritical. These new methods some advantages over classical extractions: short extraction times, less solvent requirement, less amount of waste production etc. Almost all of the researchers focus on the type of flavonoid and the amount found in the plant material, but they do not deal with the the economics, and thus the optimization of the process. Response Surface Methodology is the most approved model for the optimization of any process. It is a combination of statistical and mathematical techniques used for analyzing several independent variables and also interactive effects among the variables on the response. This method has been used in several optimizations including adsorption [11], extraction [12], fermentation [13], and production processes [14].

In the light of the lierature cited above, the aim of the study was determined as optimization of ultrasonic extraction of total flavonoids from cinnamon for its possible use in controlled drug releasing applications in cancer treatment. In order to investigate the combinational effects of the parameters, a software program called Design-Expert used with Response Surface Methodology due to the fact that this method has an advantage of prediction of the effects of several parameters simultaneously without doing any more experiment [1114]. Three-dimensional extraction surfaces are constructed by the software. The derivation of an industrially applicable equation representing the extraction surface of the quercetin equivalents of total flavonoids of the cinnamon via ultrasonic extraction was also realized.

\section{MATERIAL and METHODS}

Cinnamonum zeylaniccum was purchased from a herbalist and the analytical grade chemicals (aluminum chloride, sodium acetate, and acetic acid) were purchased from Sigma Co. The experimental design optimization was applied in two steps; firstly single-parameter optimization was used by changing the range of the selected parameter while keeping all the others at their respective value, and then multiple-parameter was achieved with threeparameter-and-three-level Box-Behnken Design by using the results of the single-parameter optimization. 
In order to study the effects of temperature, solid-to-liquid ratio, and time on the extracted amount of total flavonoids, independent variables were coded according to (1) in multipleparameter optimization studies:

$$
x_{i}=\frac{x_{i}-x_{0}}{\Delta x}
$$

where $x_{i}$ is the dimensionless coded value of $i$ th independent variable, $x_{0}$ is the value of $x_{i}$ at the center point, and $\Delta x$ is the step change value. The parameters of the study were summarized in Table 1. The center points (coded as " 0 ") of the parameters were obtained from the singleparameter optimization results.

Table 1 Box-Behnken Design parameters used in the study

\begin{tabular}{llll}
\hline Parameters & $\mathbf{- 1}$ & $\mathbf{0}$ & $\mathbf{+ 1}$ \\
\hline $\mathrm{x}_{1}$ : Extraction temperature $\left({ }^{0} \mathrm{C}\right)$ & 30 & 40 & 50 \\
$\mathrm{x}_{2}$ : Extraction time $(\mathrm{min})$ & 5 & 15 & 25 \\
$\mathrm{x}_{3}:$ Solid/liquid $(\mathrm{g} / \mathrm{ml})$ & $1 / 10$ & $1 / 30$ & $1 / 50$ \\
\hline
\end{tabular}

The surface of the system is explained by the polynomial model given in (2) and higher orders:

$$
Y=\beta_{0}+\sum_{i=1}^{k} \beta_{i} x_{i}+\sum_{i=1}^{k} \beta_{i i} x_{i}^{2}+\sum_{i=1}^{k-1} \sum_{j=2}^{k} \beta_{i j} x_{i} x_{j}+\varepsilon
$$

where $Y$ is the predicted response, $x_{i}, x_{j}, \ldots, x_{k}$ are input variables, which affect the response $Y$, $x_{i}^{2}, x_{j}^{2}, \ldots, x_{k}^{2}$ are the square effects, $\beta_{0}$ is the intercept term, $x_{i} x_{j}, x_{j} x_{k}$ and $x_{i} x_{k}$ are the interaction effects, $\beta_{i}(i=1,2, \ldots, k)$ is the linear effect, $\beta_{i i}(i=1,2, \ldots, k)$ is the squared effect, $\beta_{i j}(i$ $=1,2, \ldots, k)$ is the interaction effect, and $\varepsilon$ is the random error [15], [16].

The Design-Expert 9.0 (Stat-Ease Inc., Minneapolis, MN, USA) software was used for regression and graphical analysis of the experimental data to fit the equations developed and evaluation of their statistical significance. BBD is frequently used under response surface method due to its suitability to fit quadratic surface that usually works well for process optimization. The optimum values of the selected variables were obtained by solving the regression equation at desired values of the process responses was fixed at the optimization criteria.

Classical extraction was realized batch-wise in a $250 \mathrm{~mL}$ Erlenmeyer flask with methanol as a solvent according to the Box-Behnken design conditions. Ultrasound application was set at sweep mode at all extractions. At the end of the extraction, the content of the flask was filtered through $110 \mathrm{~mm}$ filters (FilterLab) and filtered samples were used for quercetin equivalent of total flavonoid analysis. Quercetin was measured by colorimetric method of aluminum chloride [17]. $1 \mathrm{ml}$ of sample was mixed with acetic acid-sodium acetate buffer solution of $\mathrm{pH}-4$ and $2 \mathrm{ml}$ of $\mathrm{AlCl}_{3}$ solution. The absorbance of the resultant solution was recorded at $415 \mathrm{~nm}$ by UV-Spectrophotometer (LANGF, DR 5000). In the analysis, methanolbuffer containing blank was used. The amount of quercetin equivalent of total flavonoids extracted were calculated with the $(3)\left(\mathrm{R}^{2}=0.9997\right)$ derived from the absorbance values of solutions prepared by solving different amounts of pure quercetin in a $200 \mathrm{ml}$ of methanol.

$$
\text { Absorbance@415nm=(0.0025).Concentration }(\mathrm{mg} / \mathrm{g})+0.0192
$$




\section{RESULTS and DISCUSSIONS}

In the study, the results of batch experiments at the conditions of Box-Behnken design were summarized in Table 2. They were entered into the software, and statistical tests were applied in each of the suggested functions of Design-Expert program. The model having the highest regression coefficient and the lowest coefficient of variance value was chosen as the predicted best function for representation of the extraction surface. Those values for the suggested reduced cubic model of the software were 0.9998 and 1.05 , respectively. The predicted R-squared was found reasonably in agreement with the R-squared value of the model. The symmetrical relationship between the experimental data (actual) and their respective calculated values from the function (predicted) approved the applicability of the function chosen (Fig. 1). As a result, the model function was chosen as reduced cubic model.

Table 2. Box-Behnken Design and experimental results.

\begin{tabular}{llllll}
\hline No & $\mathrm{x}_{1}$ & $\mathrm{x}_{2}$ & $\mathrm{x}_{3}$ & Absorbance $@ 415 \mathrm{~nm}$ & Quercetin eq.of total flavonoids $(\mathrm{mg})$ \\
\hline 1 & -1 & -1 & 0 & 0.0420 & 0.7776 \\
2 & +1 & -1 & 0 & 0.0752 & 1.5744 \\
3 & -1 & +1 & 0 & 0.0955 & 2.0616 \\
4 & +1 & +1 & 0 & 0.1061 & 2.3160 \\
5 & -1 & 0 & -1 & 1.5518 & 12.3376 \\
6 & +1 & 0 & -1 & 0.9745 & 7.7192 \\
7 & -1 & 0 & +1 & 0.1006 & 1.6280 \\
8 & +1 & 0 & +1 & 0.1228 & 2.0720 \\
9 & 0 & -1 & -1 & 0.9251 & 7.3240 \\
10 & 0 & +1 & -1 & 0.9402 & 7.4448 \\
11 & 0 & -1 & +1 & 0.0613 & 0.8420 \\
12 & 0 & +1 & +1 & 0.1248 & 2.1120 \\
13 & 0 & 0 & 0 & 0.7207 & 5.6888 \\
14 & 0 & 0 & 0 & 0.7096 & 5.6000 \\
15 & 0 & 0 & 0 & 0.7172 & 5.6608 \\
\hline
\end{tabular}
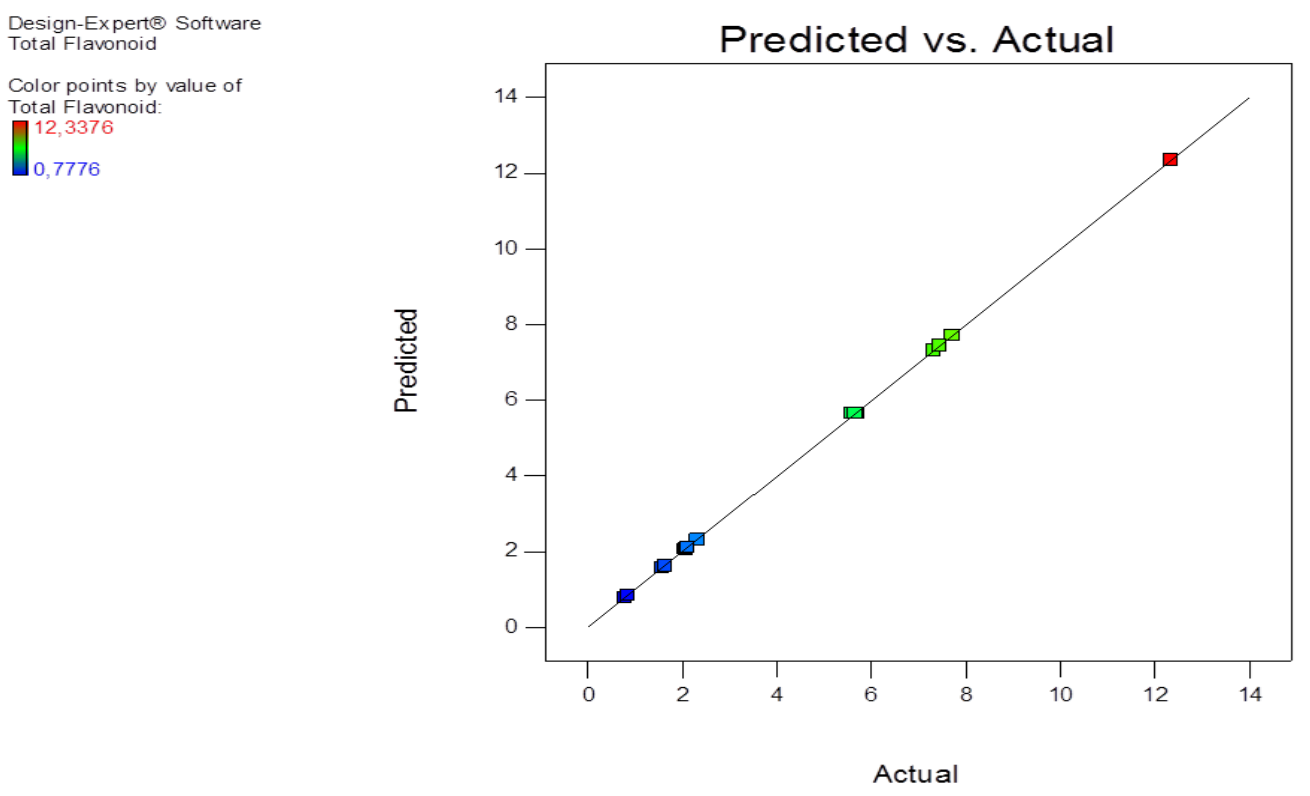

Figure 1. Statistical approval of the reduced cubic model 
The Analysis of Variance (ANOVA) for the reduced cubic model was constructed by the software (Table 3). In that, A demonstrates the temperature; $\mathrm{B}$ and $\mathrm{C}$ were representing time and solid-to-liquid ratio, respectively. In the statistical analysis, the reduced cubic model was "significant", lack of fit was "insignificant", and model had nearly $0.004 \%$ pure error. The larger the magnitude of the F-value and the smaller the p-value, the more significant the effect of corresponding parameter on the yield of extraction. Thus, according to the ANOVA table, the most effective single parameter on the extraction of quercetin equivalent of total flavonoid from Cinnamonnum zeylaniccum were found as solid-to-liquid ratio, followed by the extraction temperature. This result was acceptable since at higher temperatures, the solubility of flavonoids increases and also as the ultrasound application time increases the solvent diffusion into the solid plant particles increases. Additionally, the results showed that temperature and the solid-to-liquid parameters were mostly interrelated parameters on this operation. The same relation was also observed in our previous research considering the microwave-assisted extraction of flavonoids from the same plant [18].

Generally, second order polynomials found as the most appropriate functions when response surface methodology was applied to the systems [18]. This observation results from the interrelation of parameters on the process response. If all of the parameters are highly interrelated with the other, then quadratic model was acceptable. However, as in this study, the interactive effects between some of the parameters (Figure 2) were well representable with the reduced cubic model then the quadratic one.

Table 3. Analysis of variance (ANOVA) for reduced cubic function model

\begin{tabular}{lccccc}
\hline Source & $\begin{array}{l}\text { Sum of } \\
\text { Squares }\end{array}$ & \multirow{2}{*}{$\mathrm{df}$} & $\begin{array}{l}\text { Mean } \\
\text { Square }\end{array}$ & $\begin{array}{l}\mathrm{F} \\
\text { Value }\end{array}$ & $\begin{array}{c}\text { p-value } \\
\text { Prob > F }\end{array}$ \\
\hline Model & 158,40 & 12 & 13,20 & 6404,51 & 0,0002 \\
A-Temperature & 4,36 & 1 & 4,36 & 2113,72 & 0,0005 \\
B-Time & 0,48 & 1 & 0,48 & 234,63 & 0,0042 \\
$C$-Solid/liquid & 34,90 & 1 & 34,90 & 16932,14 & $<0.0001$ \\
$A B$ & 0,074 & 1 & 0,074 & 35,69 & 0,0269 \\
$A C$ & 6,41 & 1 & 6,41 & 3108,65 & 0,0003 \\
$B C$ & 0,33 & 1 & 0,33 & 160,20 & 0,0062 \\
$A^{2}$ & 5,58 & 1 & 5,58 & 2708,09 & 0,0004 \\
$B^{2}$ & 27,68 & 1 & 27,68 & 13430,08 & $<0.0001$ \\
$C^{2}$ & 8,52 & 1 & 8,52 & 4132,64 & 0,0002 \\
$A^{2} B$ & 0,050 & 1 & 0,050 & 24,44 & 0,0386 \\
$A^{2} C$ & 2,58 & 1 & 2,58 & 1251,19 & 0,0008 \\
A $B^{2}$ & 3,41 & 1 & 3,41 & 1656,16 & 0,0006 \\
Pure Error & $4,122 \mathrm{E}-003$ & 2 & $2,061 \mathrm{E}-003$ & & \\
Core Total & 158,40 & 14 & & & \\
\hline
\end{tabular}

Model: Significant; Lack of fit: Not significant; R-Squared: 1.0000; Predicted R-Squared: 0.9998 
Design-Expert@ Software

Factor Coding: Actual

Total Flavonoid $(\mathrm{mg} / \mathrm{g})$

- Design points above predicted value

Design points below predicted value

12,3376

0,7776

$\mathrm{X} 1=\mathrm{C}: \mathrm{S} / \mathrm{L}$

$\mathrm{X}_{2}=\mathrm{A}:$ Temperature

Actual Factor

B: Time $=0$

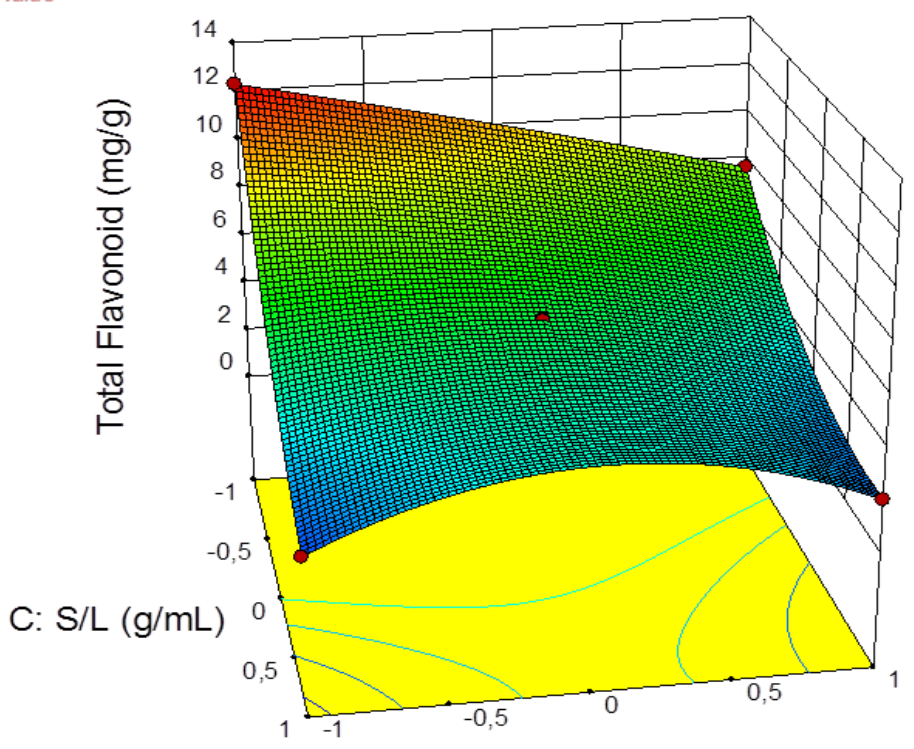

A: Temperature (oC)

Figure 2. Three-dimensional response surface of extraction yield depending on solid-to-liquid ratio and temperature

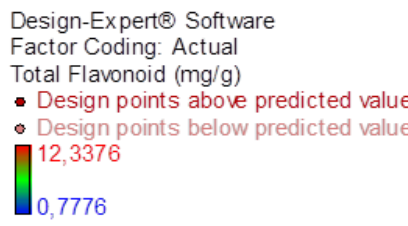

$\mathrm{X} 1=\mathrm{C}: \mathrm{S} / \mathrm{L}$

$\mathrm{X} 2=\mathrm{B}$ : Time

Actual Factor

A: Temperature $=0$

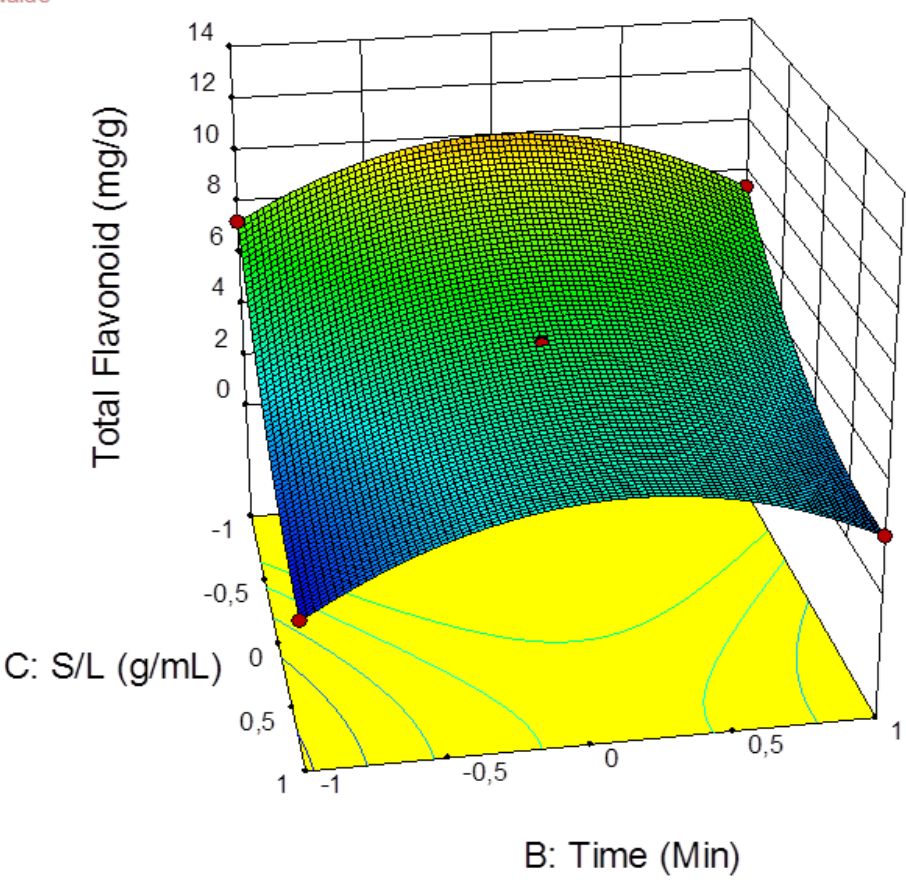

Figure 3. Three-dimensional response surface of extraction yield depending on solid-to-liquid ratio and time 


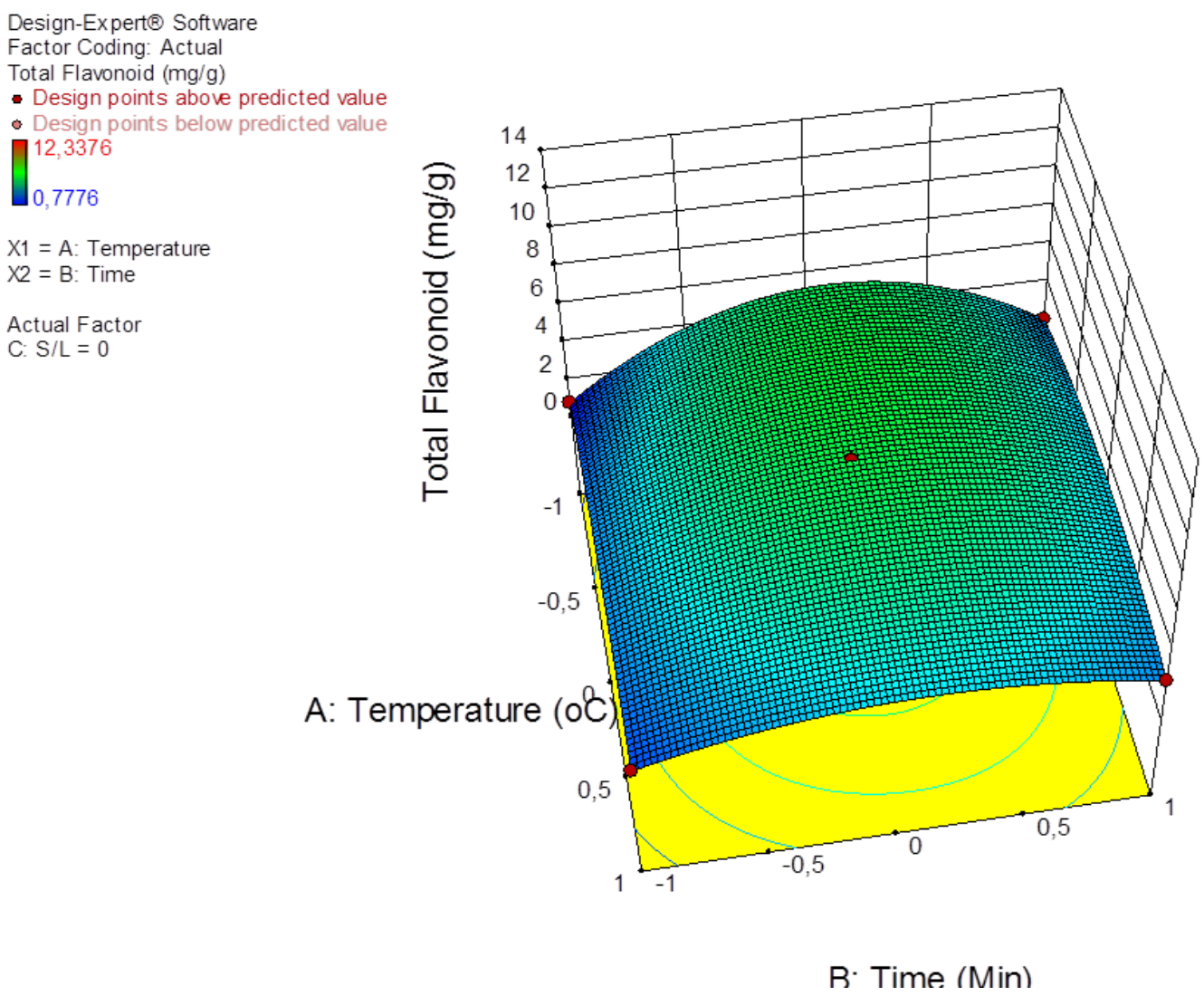

Figure 4. Three-dimensional response surface of extraction yield depending on temperature and time

At this point, three-dimensional response surfaces were constructed in this study by using software. The interactive effects of the parameters were shown in Figures 2-4. In those, red regions shows the highest amount of total flavonoids extracted, yellow and blue parts represent the lower and much lower extraction yields than those. As it can be seen from figures, solid-toliquid ratio and the extraction temperature combinations can produce the highest yield, and neither temperature-and-time nor solid-to-liquid ratio-time combinations can reach it. As it can be concluded from ANOVA table and Figure 4, extraction temperature and time relations were so low. In order to reach the highest flavonoid amount, both the solid-to-liquid ratio and the temperature must be in the coded range of $[-0.5 ;-1]$ (Figure 2 ).

\section{CONCLUSION}

In this study our aim was to optimize the ultrasonic extraction conditions of quercetin equivalent of total flavonoids from Cinnamonnum zeylaniccum by investigating the effect of parameters for each and also in combination. In addition, in order to use the results of the study in an industrial production processes, modeling equation was derived. According to the results of statistical analysis, reduced cubic model function was chosen as the resultant equation (Eqn. 4) for the industrial production of flavonoids from this plant:

Quercetin eq. of total flavonoids $=5.65-(1.04) A+(0.35) B-(2.95) C-$ $(0.14) A B+(1.27) A C+(0.29) B C-(1.23) A^{2}-(2.74) B^{2}+(1.52) C^{2}+(0.16) A^{2} B-$ $(1.14) A^{2} C+(1.31) A B^{2}$

Finally, the required extraction conditions were analyzed by using this equation and numerical analysis section of the software. In the analysis, restrictions of the parameters were selected as "in range" (has a meaning that they are in the experimental range), and the response 
criterion was determined as "max". As a result of the multi-parameter optimization, the optimum conditions producing the highest yield $(12.34 \mathrm{mg} \mathrm{QAE} / \mathrm{g})$ were determined as $30^{\circ} \mathrm{C}$, 15 minutes, $1 / 10 \mathrm{~g} / \mathrm{mL}$. Also, it was determined that, the yield was not directly proportional with the solid plant material used. The highest flavonoid amount increased up to $19 \mathrm{mg}$ (data is not shown). As a conclusion ultrasonic extraction was found much more effective method than the microwave-assisted extraction [18] of flavonoids from this plant.

\section{Conflict of Interests}

Authors declare that there is no conflict of interests.

\section{REFERENCES}

[1] Yıldırım, M. E., Canbal, M., Ozyuvali, E., \& Karataş, Ö. F. (2016). Urological recommedations of Hadji Pasha's, a Turkish aged doctor in Anatolia. Avicenna journal of phytomedicine, 6(5), 502.

[2] Murakami, A., Ashida, H., \& Terao, J. (2008). Multitargeted cancer prevention by quercetin. Cancer letters, 269(2), 315-325.

[3] Pavun, L., Đurđević, P., Jelikić-Stankov, M., Đikanović, D., Ćirić, A., \& UskokovićMarković, S. (2014). Spectrofluorimetric determination of quercetin in pharmaceutical dosage forms. Macedonian Journal of Chemistry and Chemical Engineering, 33(2), 209215.

[4] Jeong, J. H., An, J. Y., Kwon, Y. T., Rhee, J. G., \& Lee, Y. J. (2009). Effects of low dose quercetin: Cancer cell-specific inhibition of cell cycle progression. Journal of cellular biochemistry, 106(1), 73-82.

[5]Canivenc-Lavier, M. C., Vernevaut, M. F., Totis, M., Siess, M. H., Magdalou, J., \& Suschetet, M. (1996). Comparative effects of flavonoids and model inducers on drugmetabolizing enzymes in rat liver. Toxicology, 114(1), 19-27.

[6] Moon, Y. J., Wang, X., \& Morris, M. E. (2006). Dietary flavonoids: effects on xenobiotic and carcinogen metabolism. Toxicology in vitro, 20(2), 187-210.

[7] Liu, Y., \& Guo, M. (2015). Studies on transition metal-quercetin complexes using electrospray ionization tandem mass spectrometry. Molecules, 20(5), 8583-8594.

[8] Cornard, J. P., \& Merlin, J. C. (2002). Spectroscopic and structural study of complexes of quercetin with Al (III). Journal of Inorganic Biochemistry, 92(1), 19-27.

[9] Tan, Q., Liu, W., Guo, C., \& Zhai, G. (2011). Preparation and evaluation of quercetinloaded lecithin-chitosan nanoparticles for topical delivery. International journal of nanomedicine, 6, 1621.

[10] Balcerzak, M., Tyburska, A., \& Święcicka-Füchsel, E. (2008). Selective determination of Fe (III) in Fe (II) samples by UV-spectrophotometry with the aid of quercetin and morin. Acta pharmaceutica, 58(3), 327-334.

[11] Turkyilmaz, H., Kartal, T., \& Yildiz, S. Y. (2014). Optimization of lead adsorption of mordenite by response surface methodology: characterization and modification. Journal of Environmental Health Science and Engineering, 12(1), 5.

[12] Goktas, F. M., Sahin, B., \& Yigitarslan, S. (2015). Production of sterilizing agents from Calendula officinalis extracts optimized by response surface methodology. International journal of analytical chemistry, 2015.

[13] Dashtianeh, M., Vatanara, A., Fatemi, S., \& Sefidkon, F. (2013). Optimization of supercritical extraction of Pimpinella affinis Ledeb. using response surface methodology. Journal of CO2 Utilization, 3, 1-6. 
[14] Levin, L., Herrmann, C., \& Papinutti, V. L. (2008). Optimization of lignocellulolytic enzyme production by the white-rot fungus Trametes trogii in solid-state fermentation using response surface methodology. Biochemical Engineering Journal, 39(1), 207-214.

[15] Zhao, Y., Hou, Y., Tang, G., Cai, E., Liu, S., Yang, H., ... \& Wang, S. (2014). Optimization of ultrasonic extraction of phenolic compounds from Epimedium brevicornum maxim using response surface methodology and evaluation of its antioxidant activities in vitro. Journal of analytical methods in chemistry, 2014.

[16] Sun, Z., Su, R., Qiao, J., Zhao, Z., \& Wang, X. (2014). Flavonoids extraction from Taraxacum officinale (Dandelion): optimisation using response surface methodology and antioxidant activity. Journal of Chemistry, 2014.

[17] Chang, C. C., Yang, M. H., Wen, H. M., \& Chern, J. C. (2002). Estimation of total flavonoid content in propolis by two complementary colorimetric methods. Journal of food and drug analysis, 10(3).

[18] Hesap, E., \& Yigitarslan, S. Investigation of Microwave-assisted Extraction Conditions of Quercetin from Cinnamonum zeylaniccum with Response Surface Methodology. Parameters, 1,0 . 